Jurnal Indonesia Sosial Teknologi: p-ISSN: 2723 - 6609

e-ISSN : 2548-1398

Vol. 1, No. 3 Oktober 2020

\title{
PENERAPAN SIX SIGMA DENGAN MENGGUNAKAN PENDEKATAN TAGUCHI UNTUK PROSES PRODUKSI ELEKTROPLATING PRODUK SPRING TENSION 35086 PADA PT. TETRA MITRA SINERGIS
}

\author{
Habib Fiki Wahyudi, Zeny Fatimah Hunusalela dan Anggi Oktaviani \\ Universitas Indraprasta PGRI \\ Email: habibfikiwahyudi12@gmail.com,zeny.fh86@gmail.com, \\ Anggioktaviani.mt@gmail.com
}

\begin{abstract}
Abstrac
The most important factor for achieving company success in industrial competition is quality. In the industrial world, quality control is the key to maintaining customer loyalty. Quality control is needed by a company so that it can take corrective actions against irregularities in the production process, so the company can take anticipatory action by making corrective steps for the next production process. By carrying out quality control, it is expected to achieve the company's objectives, related to quality management. PT. Tetra Mitra Sinergis makes efforts to improve quality by reducing defective products. The Six Sigma method with the Taguchi approach can be used to improve product yarn quality. From the analysis it can be seen that the sigma value that has been achieved is 3.37 , it shows that the company is in pretty good condition, but there are still some deficiencies that result in defective products. So, product quality must be improved. With the Taguchi method we can find out the factors and the optimal level to improve product quality. These factors and levels are factor A level 3 with a coating time of 4 minutes. Then factor B level 1 with a reaction temperature of $300 \mathrm{C}$. Then factor $\mathrm{C}$ level 3 with a voltage / voltage of 6 volts. Then factor D level 3 with $1.4 \%$ solution concentration.he abstract should not exceed 250 words. It should briefly summarize the essence of the paper and address the following areas without using specific subsection titles.): Objective: Briefly state the problem or issue addressed, in language accessible to a general scientific audience. Technology or Method: Briefly summarize the technological innovation or method used to address the problem. Results: Provide a brief summary of the results and findings. Conclusions: Give brief concluding remarks on your outcomes. Detailed discussion of these aspects should be provided in the main body of the paper. There should no nonstandard abbreviations, acknowledgments of support, references or footnotes in in the abstract.
\end{abstract}

Keywords - Quality Control, Six Sigma, Taguchi, Fishbone Diagram

\begin{abstract}
Abstrak
Faktor terpenting untuk mencapai kesuksesan perusahaan dalam persaigan industri adalah kualitas. Dalam dunia industri, kontrol kualitas adalah kunci untuk mempertahankan loyalitas pelanggan. Pengendalian kualitas sangat diperlukan oleh sebuah perusahaaan agar dapat melakukan tindakan koreksi terhadap terjadinya
\end{abstract}


Penerapan Six Sigma Dengan Menggunakan Pendekatan Taguchi Untuk Proses Produksi Elektroplating Produk Spring Tension 35086 Pada PT. Tetra Mitra Sinergis

penyimpangan dalam proses produksi, sehingga perusahaan dapat melakukan tindakan antisipasi dengan melakukan langkah perbaikan untuk proses produksi berikutnya. Dengan melakukan kontrol kualitas diharapkan dapat mencapai tujuan perusahaan, terkait dengan management kualitas. PT. Tetra Mitra Sinergis melakukan upaya untuk peningkatan kualitas dengan mengurangi produk cacat. Metode Six Sigma dengan pendekatan Taguchi dapat digunakan untuk meningkatkan kualitas benang produk. Dari hasil analisis dapat diketahui nilai sigma yang telah dicapai adalah 3,37 ini menunjukan perusahaan dalam kondisi cukup baik namun masih terdapat beberapa kekurangan yang mengakibatkan terjadi produk cacat. Jadi, kualitas produk harus di tingkatkan. Dengan metode Taguchi kita dapat mengetahui faktor-faktor dan level optimal untuk meningkatkan kualitas produk. Faktor dan level tersebut adalah faktor A level 3 dengan waktu pelapisan 4 menit. Kemudian faktor B level 1 dengan suhu reaksi 300C. Kemudian faktor C level 3 dengan tegangan/voltase 6 volt. Kemudian faktor D level 3 dengan konsentrasi larutan $1,4 \%$.

Kata Kunci: Pengendalian Kualitas,Six Sigma, Taguchi, Fishbone Diagram

\section{Pendahuluan}

Perkembangan perindustrian pada saat ini sangat pesat mengingat banyak perusahaan-perusahaan baru yang mulai tumbuh dan berkembang tidak hanya di dalam negeri tetapi sudah mencapai kancah internasional. Perusahaan-perusahaan tersebut berlomba-lomba dalam meningkatkan kualitas perusahaannya, upaya yang dilakukan untuk meningkatkan kualitas perusahaan dengan menggunakan sistem manajemen yang berorientasi pada mutu atau kualitas sesuai dengan kebutuhan dan persyaratan pelanggan lalu diterapkan dalam proses produksi untuk menjamin kualitas produk atau jasa. Salah satu tantangan yang dihadapi oleh organisasi/perusahaan penyedia jasa maupun produk adalah tuntutan masyarakat/pelanggan akan kebutuhan jasa dan produk yang semakin beragam dan meningkat seiring dengan laju perkembangan, sehingga peningkaatan mutu dan kualitas pada suatu perusahaaan kini menjadi prioritas utama guna untuk memberikan layanan serta kepuasan yang maksimal terhadap masyarakat/pelanggan sesuai dengan yang mereka butuhkan baik secara efektif maupun efisien (Sufandy, 2018). Seiring dengan perkembangan ilmu pengetahuan dan teknologi, konsumen menjadi perhatian utama bagi para pengusaha/pemilik perusahaan. Maraknya produk-produk dengan fungsi dan bentuk yang hampir sama menjadikan kualitas hal utama yang menjadi tolak ukur keberhasilan suatu perusahaan, dimana dengan mengutamakan kualitas sebuah perusahaan berusaha menyediakan produk-produk berkualiatas dengan harga yang terjangkau. Pengendalian kualitas adalah kegiatan yang dilakukan untuk menjaga konsistensi kualitas produk dan jasa yang dihasilkan agar sesuai dengan tuntutan kebutuhan pasar (Schroeder, Goldstein, \& Rungtusanatham, 2011). Secara umum pengendalian kualitas dapat diartikan sebagai suatu sistem yang tepat untuk memadukan usaha pengembangan, pelestarian, dan upaya peningkatan kualitas di dalam perusahaan, guna mencapai kesesuaian untuk dipakai dan kepuasan pemakai (Gusniar, 2012). Sedangkan menurut (Harsanto, 2017), Pengendalian kualitas 
merupakan suatu kegiatan yang dilakukan oleh perusahaan untuk menjaga agar produk yang dihasilkan tetap sesuai dengan spesifikasi yang telah ditentukan. Cara tersebut yang diharapkan untuk dapat menarik konsumen baru sehingga diharapkan akan membuat konsumen setia/loyal pada akhirnya. PT. Tetra Mitra Sinergis merupakan salah satu industri yang bergerak di bidang industri jasa elektroplating (pelapisan logam) untuk komponen-komponen kendaraan bermotor, PT. Tetra Mitra Sinergis melakukan proses finishing part sehingga menjadi Barang Jadi. Terdapat tiga proses pengecekan yang dilakukan oleh PT. Tetra Mitra sinergis yaitu: pengecekan barang incoming, pengecekan proses produksi, pengecekan barang outgoing. Proses pengecekan di perusahaan ini belum maksimal karena Kurangnya komunikasi antar sesama karyawan dan karyawan dengan atasan yang menyebabkan Kurangnya kesadaran karyawan akan kualitas atau mutu produk yang dihasilkan, Sehingga banyak produk yang dilakukan proses Replating. Hal ini dipengaruhi oleh Budaya yang tertanam dalam diri karyawan yaitu mengedepankan produksi dibanding kualitas. Sehingga banyak keluhan pelanggan tentang produk yang dihasilkan Pt. Tetra Mitra Sinergis, rata-rata pelanggan mengeluh karena banyak produk yang dihasilkan berkualitas rendah. Perusahaan telah menetapkan standar persentase cacat sebesar $4 \%$ dari jumlah produksi, berikut adalah laporan produksi produk Spring Tension 35086.

Tabel I. Data Produksi Perusahaan

\begin{tabular}{|c|c|c|c|c|c|}
\hline \multirow[b]{2}{*}{ Bulan } & \multirow[b]{2}{*}{$\begin{array}{c}\text { Jumlah } \\
\text { produksi }\end{array}$} & \multicolumn{2}{|c|}{ Jenis Cacat } & \multirow[b]{2}{*}{$\begin{array}{c}\text { Jumlah } \\
\text { Cacat }\end{array}$} & \multirow{2}{*}{$\begin{array}{c}\text { Persentase } \\
\text { Cacat }\end{array}$} \\
\hline & & $\begin{array}{l}\text { Cacat } \\
\text { Warna }\end{array}$ & $\begin{array}{l}\text { Cacat } \\
\text { Fisik }\end{array}$ & & \\
\hline Juli & 2550 & 112 & 8 & 120 & $4,7 \%$ \\
\hline Agt & 2000 & 42 & 7 & 49 & $2,5 \%$ \\
\hline Sept & 2300 & 70 & 10 & 80 & $3,5 \%$ \\
\hline Okt & 2600 & 118 & 9 & 127 & $4,9 \%$ \\
\hline Nov & 2500 & 73 & 6 & 79 & $3,2 \%$ \\
\hline Des & 2900 & 142 & 10 & 152 & $5,2 \%$ \\
\hline Jan & 2600 & 81 & 12 & 93 & $3,6 \%$ \\
\hline $\mathrm{Feb}$ & 2550 & 80 & 7 & 87 & $3,4 \%$ \\
\hline Mar & 2150 & 107 & 9 & 116 & $5,4 \%$ \\
\hline Apr & 2500 & 79 & 8 & 87 & $3,5 \%$ \\
\hline Mei & 2100 & 86 & 9 & 95 & $4,5 \%$ \\
\hline Juni & 2250 & 65 & 6 & 71 & $3,2 \%$ \\
\hline
\end{tabular}

Kendala-kendala tersebut, terutama yang berkaitan dengan kualitas mutu produk dapat diatasi dengan penerapan six sigma menggunakan pendekatan taguchi. Berdasarkan penelitian terdahulu oleh (Oktajayanti, Mustafid, \& Sudarno, 2016), menyatakan bahwa metode six sigma-taguchi dapat digunakan untuk memperbaiki kualitas produk dan serta dapat menekan biaya dan sumber daya seminimal mungkin. Adapun penelitian oleh 
Penerapan Six Sigma Dengan Menggunakan Pendekatan Taguchi Untuk Proses Produksi Elektroplating Produk Spring Tension 35086 Pada PT. Tetra Mitra Sinergis

(Asfar, Tjahjaningsih, \& Haryono, 2018), menjelaskan bahwa terdapat beberapa faktor yang mempengaruhi kualitas produk diantaranya yaitu kualitas bahan baku dan gangguan pada proses-proses produksi. Diperkuat oleh Dian Anggraini, Shanty Kusuma (Anggraini, Dewi, \& Saputro, 2015), yang menyatakan Salah satu metode yang dapat digunakan untuk mengidentifikasi faktor-faktor yang mempengaruhi kualitas dan menentukan komposisi yang tepat adalah dengan menggunakan desain eksperimen Taguchi. Penerapan metode six sigma menggunakan pendekatan Taguchi untuk megidentifikasi dan upaya meningkatkan kualitas produk (Ramayanti, Fitriyeni, \& Yulistyari, 2019). Adapun penelitian yang dilakukan oleh (Shofia, Mustafid, \& Sudarno, 2015), menyatakan bahwa pengecekan tingkat kualitas produk di perusahaan dapat menggunakan metode Six Sigma. Six Sigma merupakan usaha peningkatan berkelanjutan sebagai respon atas kebutuhan organisasi manufaktur untuk tetap kompetitif dengan cara meningkatkan kualitas mereka, mengurangi variabilitas proses, dan mengurangi biaya dari permasalahan kualitas (Ramayanti et al., 2019). Langkah mengurangi cacat dan variasi dilakukan secara sistematis dengan mendefinisikan, mengukur, menganalisa, memperbaiki, dan mengendalikannya yang dikenal dengan 5 fase DMAIC (Caesaron \& Simatupang, 2015). Untuk mengetahui terjadinya setiap jenis kecacatan maka digunakan diagram pareto (pareto chart), dimana diurutkan dari jenis kecacatan yang memiliki frekuensi kejadian yang paling tinggi ke jenis kecacatan dengan frekuensi kejadian yang paling rendah (Wijaya \& Sutapa, 2013). Pareto chart berfungsi untuk mengidentifikasi beberapa isu vital dengan menerapkan aturan perbandingan 80:20, artinya $80 \%$ peningkatan dapat dicapai dengan memecahakan $20 \%$ masalah terpenting yang dihadapi (Yamit, 2010). Setelah diketahui jenis kecacatan dengan frekuensi tertinggi maka penting diketahui faktor-faktor dominan yang perlu dikendalikan. Faktor-faktor dominan yang perlu dikendalikan dapat diketahui dengan menggunakan diagram sebab akibat. Diagram sebab akibat memiliki fungsi dasar untuk untuk mengidentifikasi dan mengorganisasi penyebab-penyebab yang mungkin timbul dari suatu efek spesifik dan kemudian memisahkan akar penyebabnya (Yamit, 2010). Penggunaan Taguchi method diperlukan untuk menemukan kombinasi faktor-level yang bersifat robust (kokoh) tak terpengaruh oleh faktor-faktor pengganggu, karenanya metode ini disebut juga sebagai perancangan kokoh (robust design) (Ramayanti et al., 2019).

\section{Metode Penelitian}

\section{A. Taguchi}

Metode Taguchi merupakan suatu metodologi baru dalam bidang teknik yang bertujuan untuk memperbaiki kualitas produk dan proses dalam waktu yang bersamaan menekan biaya dan sumber daya seminimal mungkin. Metode Taguchi berupaya mencapai sasaran itu dengan menjadikan produk atau proses tidak sensitif terhadap berbagai faktor seperti misalnya material, perlengkapan manufaktur, tenaga kerja manusia dan kondisi-kondisi operasional. Metode Taguchi menjadikan produk atau proses bersifat kokoh (robust) terhadap faktor 
gangguan, karenanya metode ini disebut juga sebagai perancangan kokoh (robust design) (Soejanto, 2009).

\section{B. Six Sigma}

Sigma menunjukkan standar deviasi dari suatu proses. Standar deviasi digunakan unutk mengukur variasi atau jumlah persebaran rata-rata suatu data. Nilai sigma ini digunakan untuk menunjukkan seberapa sering cacat mungkin terjadi. Semakin tinggi nilai sigma maka semakin kecil toleransi kecacatan dari suatu aktivitas, yang mana membuat semakin tinggi kapabilitas prosesnya. Hal ini berarti bahwa semakin tinggi nilai sigma yang dimiliki oleh organisasi maka semakin baik pula performansi yang diberikan. Menurut Stevenson dan Chuong (2014) "Six Sigma adalah sebuah proses bisnis untuk memperbaiki mutu, mengurangi biaya, dan meningkatkan kepuasan pelanggan."

\section{Defect Per Million Opportunities (DPMO)}

Defect adalah semua kejadian atau peristiwa dimana produk gagal memenuhi kebutuhan pelanggan ataupun tidak mampu memenuhi standar yang dibutuhkan oleh konsumen. Defect Per Opportunity (DPO) merupakan proporsi defect atas jumlah total peluang dalam sebuah kelompok dan menunjukkan jumlah defect yang akan muncul dalam satu juta kemungkinan. Level sigma dari kinerja sering diekspresikan dalam DPMO. Tingkat pencapaian sigma menurut (Oktajayanti et al., 2016).

Tabel II. Tingkat Pencapaian Sigma

\begin{tabular}{cc}
\hline $\begin{array}{c}\text { Defects per Million } \\
\text { Opportunity }\end{array}$ & Sigma Level \\
\hline 691.462 & 1 \\
308.538 & 2 \\
66.807 & 3 \\
6.210 & 4 \\
233 & 5 \\
3,4 & 6 \\
\hline
\end{tabular}

D. Waktu dan Tempat Penelitian

Kegiatan penelitian kali ini dilaksanakan pada Februari 2020. Penelitian ini dilakukan dengan melakukan pengumpulan data, analisis dan melakukan improvement untuk mendapatkan kombinasi faktor level yang kokoh (robust). Penelitian kali ini dilakukan di PT. Tetra Mitra Sinergis yang berada di Jalan Kp.Bojong Kulur No12 Jatiasih Bekasi, Jawa Barat. Dalam hal ini penelitian dilakukan pada management kualitas produk Spring Tension 35086 dengan warna plating Rainbow Cr3.

E. Metode Penelitian

Penelitian ini dilakukan karena terdapat beberapa permasalahan pada perusahaan yang berpengaruh terhadap kualitas produk yang dihasilkan, dalam hal ini adalah produk Spring Tension 35086 dengan warna plating Rainbow Cr3. Produk Spring Tension 35086 yang dihasilkan memiliki kualitas warna tidak baik sehingga terdapat produk yang harus dilakukan Replating. Untuk mengatasi masalah tersebut penelitian dilakukan menggunakan metode six sigma dengan 
Penerapan Six Sigma Dengan Menggunakan Pendekatan Taguchi Untuk Proses Produksi Elektroplating Produk Spring Tension 35086 Pada PT. Tetra Mitra Sinergis

pendekatan taguchi. Pada kegiatan penelitian ini, didapatkan metodelogi penelitian, yaitu:

1. Define, pada tahap ini di tentukan atau dimunculkan permasalahan yaitu jumlah produk cacat di perusahaan. Pada fase define dilakukan identifikasi proses produksi dengan menggunakan diagram SIPOC.

2. Measure, menentukan CTQ Lalu dilakukan perhitungan DPMO dan level sigma.

3. Analyze, menguji menggunakan diagram pareto.

4. Improve, digunakan perhitungan taguchi dengan memilih jumlah faktor dan levelnya yang bersifat kokoh.

5. Control, Pada tahap control bertujuannya untuk mengevaluasi proses perbaikan yang telah dilakukan dengan efektif dan efisien serta untuk menjaga kondisi proses agar tetap stabil. Dalam hal ini control sistem dilakukan dengan metode poka yoke. Metodelogi penelitian dibuat sesuai tahapan DMAIC.

F. Metode Pengumpulan

Pada tahap ini dilakukan beberapa aktivitas yaitu pengumpulan data perusahaan. Pengumpulan data dilakukan untuk memperoleh data dan informasi yang dibutuhkan peneliti untuk melaksanakan penelitian. Data yang dikumpulkan berupa data langsung hasil pengamatan, data hasil wawancara, serta data laporan perusahaan.

1. Pengamatan langsung

Dalam hal ini dilakukan observasi terhadap management kualitas produk yang akan di teliti di tempat dan waktu yang telah ditentukan sebelumnya.

2. Wawancara

Data wawancara diperoleh dengan mengajukan beberapa pertanyaan yg terkait dengan penelitian ini kepada karyawan yang besangkutan atau bertugas.

3. Laporan perusahaan

Data laporan perusahaan didapatkan dari data base perusahaan terkait penelitian dan produk yang akan diteliti. 


\section{G. Flowchart Penelitian}

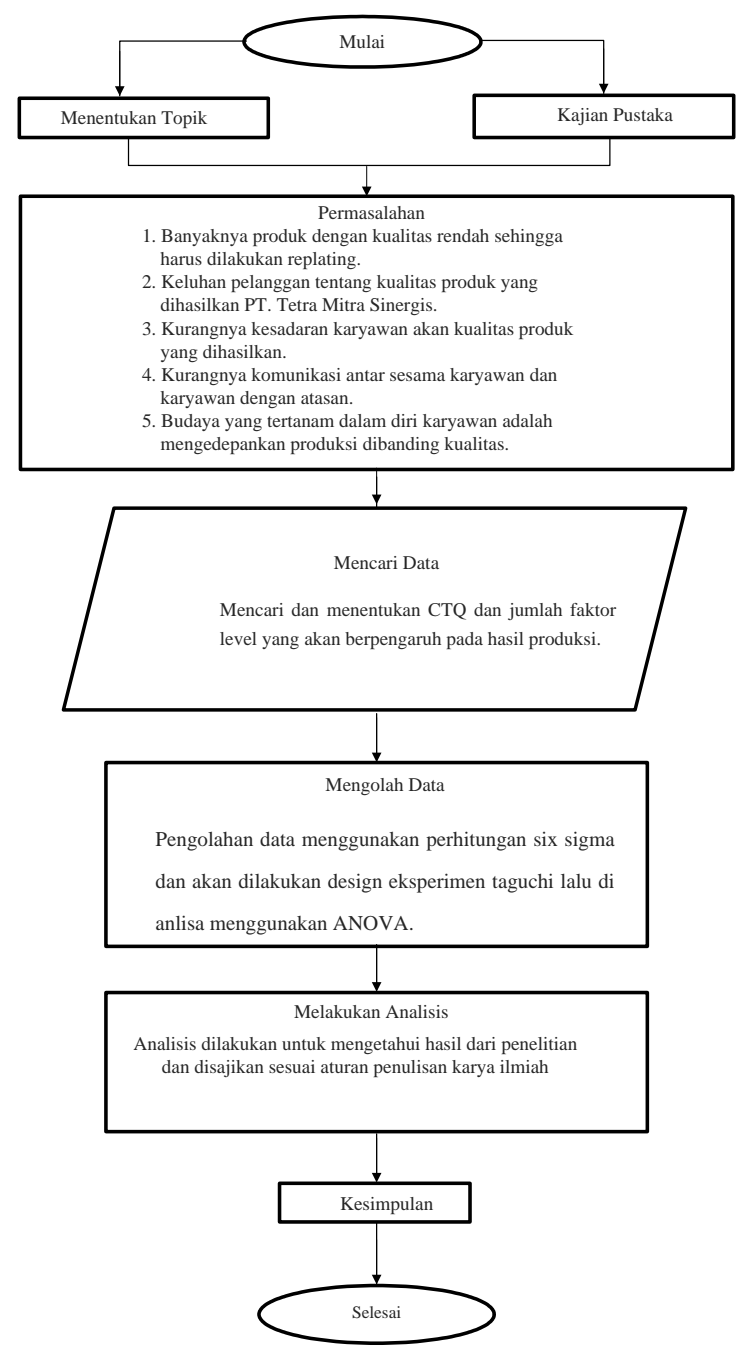

Gambar I. Flowchart Penelitian

\section{Hasil dan Pembahasan}

PT. Tetra Mitra Sinergis berdiri sejak tahun 2000 yang bergerak pada pelapisan logam dekoratif dengan nama DR Metals Plating. Seiring dengan peningkatan fasilitas produksi dan permintaan, perusahaan mulai mengerjakan barang-barang untuk kebutuhan industri terutama industri automotive. Pada tahun 2004 perusaahaan resmi menggunakan nama Tetra Mitra Sinergis. PT. Tetra Mitra Sinergis yang beralamat di Jalan Kp.Bojong Kulur No12 Jatiasih Bekasi, Jawa Barat.

A. Pengumplan Data

PT. Tetra Mitra Sinergis merupakan perusahaan industri manufaktur yang bergerak pada bidang elektroplating. Penelitian ini dilakukan karena terdapat beberapa permasalahan pada perusahaan yang berpengaruh terhadap kualitas produk yang dihasilkan, dalam hal ini adalah produk Spring Tension 35086 dengan warna plating Rainbow Cr3. Untuk Melakukan penelitian ini dibutuhkan pengumpulan data, data 
Penerapan Six Sigma Dengan Menggunakan Pendekatan Taguchi Untuk Proses Produksi Elektroplating Produk Spring Tension 35086 Pada PT. Tetra Mitra Sinergis

yang dibutuhkan adalah jenis data cacat produk, data jumlah CTQ dan faktor kombinasi, data laporan produksi perusahan.

1. Jenis Data Cacat produk

Observasi perlu dilakukan terhadap objek yang akan di teliti, dalam hal ini adalah proses plating Spring Tension 35086 dan melakukan wawancara terhadap pihak-pihak yang melakukan proses tersebut, pada penelitian ini adalah bagian produksi. Adapun CTQ yang ditentukan dalam penelitian ini adalah:

a. Karat

Cacat karat pada produk plating disebabkan karena Proses produksi kurang maksimal. karena proses plating melewati beberapa tahap, bisa saja produk kurang maksimal pada saat proses di satu atau beberapa tahap. Ada kemungkinan lain yaitu produk terlalu lama pada larutan.

b. Warna Pudar

Cacat warna pudar pada produk plating disebabkan karena proses plating kurang maksimal, biasanya terjadi pada tahap (chrometing).

c. Warna Jebol

Cacat warna jebol atau kondisi warna fisik secara visual terlihat drop/tidak berwarna, hal ini disebabkan karena part terjatuh dalam larutan pada saat proses plating.

2. Data Jumlah CTQ dan Faktor Kombinasi

Adapun jumlah cacat pada masing-masing CTQ akibat proses produksi elektroplating sebagai berikut:

Tabel III. Jumlah CTQ

\begin{tabular}{ccccc}
\hline Bulan & \multicolumn{4}{c}{ CTQ } \\
& Karat & $\begin{array}{c}\text { Warna } \\
\text { Buram }\end{array}$ & $\begin{array}{c}\text { Warna } \\
\text { Tidak } \\
\text { Rata }\end{array}$ & $\begin{array}{c}\text { Jumlah } \\
\text { Cacat }\end{array}$ \\
\hline Juli & 8 & 30 & 82 & 120 \\
Agt & 7 & 12 & 30 & 49 \\
Sept & 10 & 20 & 50 & 80 \\
Okt & 9 & 35 & 83 & 127 \\
Nov & 6 & 22 & 51 & 79 \\
Des & 10 & 40 & 102 & 152 \\
Jan & 12 & 27 & 54 & 93 \\
Feb & 7 & 23 & 57 & 87 \\
Mar & 9 & 30 & 77 & 116 \\
Apr & 8 & 25 & 54 & 87 \\
Mei & 9 & 28 & 58 & 95 \\
Juni & 6 & 21 & 44 & 71 \\
\hline
\end{tabular}


Habib Fiki Wahyudi, Zeny Fatimah Hunusalela dan Anggi Oktaviani

Sedangkan faktor kombinasi yang digunakan adalah:

Tabel IV. Kombinasi Faktor

\begin{tabular}{ccccc}
\hline Faktor & Kode & \multicolumn{3}{c}{ Level } \\
& & 1 & 2 & 3 \\
\hline Waktu pelapisan(mnt) & A & 2 & 3 & 4 \\
Suhu Reaksi(C) & B & 30 & 45 & 60 \\
Tegangan/voltase(volt) & C & 3 & 4,5 & 6 \\
Konsentrasi larutan(\%) & D & 1 & 1,2 & 1,4 \\
\hline
\end{tabular}

3. Data Laporan Produksi perusahaan

PT. Tetra Mitra Sinergis sangat memperhatikan aspek kualitas Guna menjaga kepuasan dan loyalitas custumor, dimana produk yang sudah dil akukan plating tidak melebihi persentase cacat yang telah ditetapkan perusahaan. Perusahaan telah menetapkan standar persentase cacat sebesar $4 \%$ dari jumlah produksi, berikut adalah laporan produksi produk Spring Tensioon 35086.

Tabel V. Data Produksi Perusahaan

\begin{tabular}{|c|c|c|c|c|c|}
\hline \multicolumn{6}{|c|}{$\begin{array}{c}\text { LAPORAN PRODUKSI FINISING PART PRODUK } \\
\text { SPRING TENSION } 35086 \text { BULAN JULI } 2018 \text { - JUNI } \\
2019 \\
\end{array}$} \\
\hline \multirow[b]{2}{*}{ Bulan } & \multirow[b]{2}{*}{$\begin{array}{l}\text { Jumlah } \\
\text { produksi }\end{array}$} & \multicolumn{2}{|c|}{ Jenis Cacat } & \multirow[b]{2}{*}{$\begin{array}{c}\text { Jumlah } \\
\text { Cacat }\end{array}$} & \multirow[b]{2}{*}{$\begin{array}{c}\text { Persentase } \\
\text { Cacat }\end{array}$} \\
\hline & & $\begin{array}{l}\text { Cacat } \\
\text { Warna }\end{array}$ & $\begin{array}{l}\text { Cacat } \\
\text { Fisik }\end{array}$ & & \\
\hline Juli & 2550 & 112 & 8 & 120 & $4,7 \%$ \\
\hline Agt & 2000 & 42 & 7 & 49 & $2,5 \%$ \\
\hline Sept & 2300 & 70 & 10 & 80 & $3,5 \%$ \\
\hline Okt & 2600 & 118 & 9 & 127 & $4,9 \%$ \\
\hline Nov & 2500 & 73 & 6 & 79 & $3,2 \%$ \\
\hline Des & 2900 & 142 & 10 & 152 & $5,2 \%$ \\
\hline Jan & 2600 & 81 & 12 & 93 & $3,6 \%$ \\
\hline Feb & 2550 & 80 & 7 & 87 & $3,4 \%$ \\
\hline Mar & 2150 & 107 & 9 & 116 & $5,4 \%$ \\
\hline Apr & 2500 & 79 & 8 & 87 & $3,5 \%$ \\
\hline Mei & 2100 & 86 & 9 & 95 & $4,5 \%$ \\
\hline Juni & 2250 & 65 & 6 & 71 & $3,2 \%$ \\
\hline
\end{tabular}

Berdasarkan pada tabel diatas diketahui bahwa persentase produk cacat untuk plating Spring Tension 35086 bulan juli 2018 sampai juni 2019 masih ada persentase cacat yang melebihi standar cacat perusahaan, sehingga belum memenuhi apa yang diharapkan perusahaan. Oleh karena itu perlu adanya perbaikan supaya memenuhi standar perusahaan.

B. Pengolahan Data

Setelah dilakukan pengumpulan data tahap selanjutnya adalah pengolahan data.

Pada tahap ini pengolahan data menggunkan metode six sigma dengan pendekatan taguchi. Pengolahan data akan dilakukan denngan tahapan DMAIC (Define, Measure, Analysis, Improve, Control). 
Penerapan Six Sigma Dengan Menggunakan Pendekatan Taguchi Untuk Proses Produksi Elektroplating Produk Spring Tension 35086 Pada PT. Tetra Mitra Sinergis

\section{Define}

Tahap Define merupakan tahapan awal pada proyek Six Sigma. Pada tahap Define dilakukan penggambaran proses SIPOC (Supplier, Input, Process, Output, Customers). Proses SIPOC (Supplier, Input, Process, Output, Customers) merupakan suatu proses yang digunakan dalam manajemen dan peningkatan proses, digunakan untuk mengidentifikasi seluruh elemen yang relevan dalam suatu proses perbaikan sebelum proses dilaksanakan. Adapun penggambaran diagram SIPOC untuk proses produksi elektroplating yaitu :

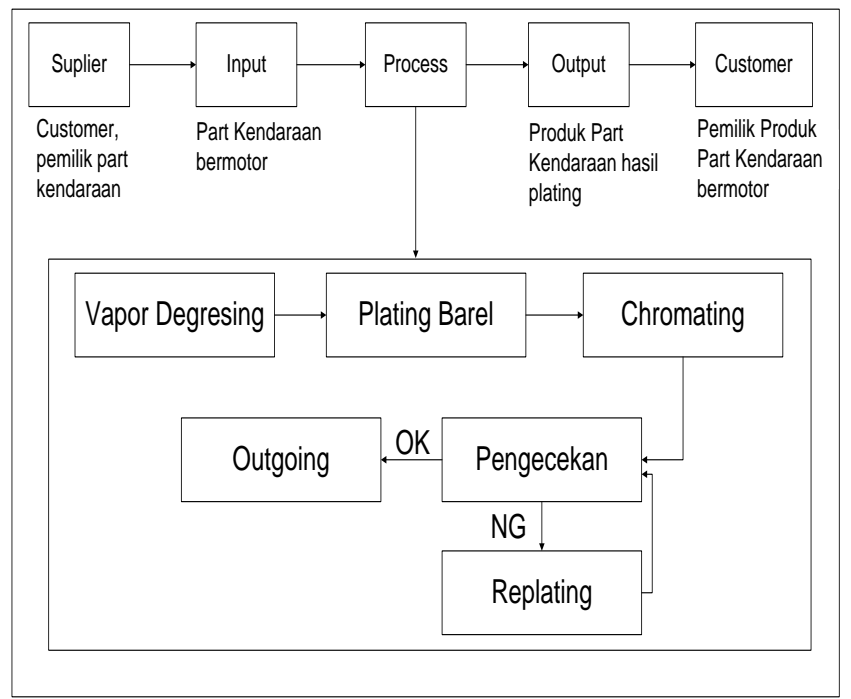

Gambar II. SIPOC elektroplating

Setelah penggambaran diagram SIPOC yang merupakan awal dalam pengolahan menggunakan metode six sigma, selanjutnya pada tahap ini akan didefinisikan CTQ (critical to quality). Untuk mengetahui permasalahan-permasalahan yang kerap kali terjadi pada produk Spring Tension 35086 maka dapat dilihat dari karakteristik kualitas beserta kriteria kecacatannya. Berikut ini adalah CTQ ( critical to quality) potensial produk Spring Tension 35086.

Tabel VI. Jenis Reject dan Jumlah Reject

\begin{tabular}{cccc}
\hline $\begin{array}{c}\text { Jenis } \\
\text { reject }\end{array}$ & $\begin{array}{c}\text { Jumlah } \\
\text { reject } \\
\text { (unit) }\end{array}$ & $\begin{array}{c}\% \\
\text { Reject }\end{array}$ & \%Kumulatif \\
\hline Karat & 101 & $8,7 \%$ & $8,7 \%$ \\
Warna & 313 & $27,1 \%$ & $35,8 \%$ \\
Buram & & & \\
Warna & & $64 \%$ & $100,0 \%$ \\
Tidak & 742 & & \\
Rata & & & \\
Total & 1156 & & \\
\hline
\end{tabular}

Tahap selanjutnya yaitu membuat diagram pareto untuk melihat lebih jelas masalah kecacatan yang merupakan prioritas untuk dilakukan perbaikan. 


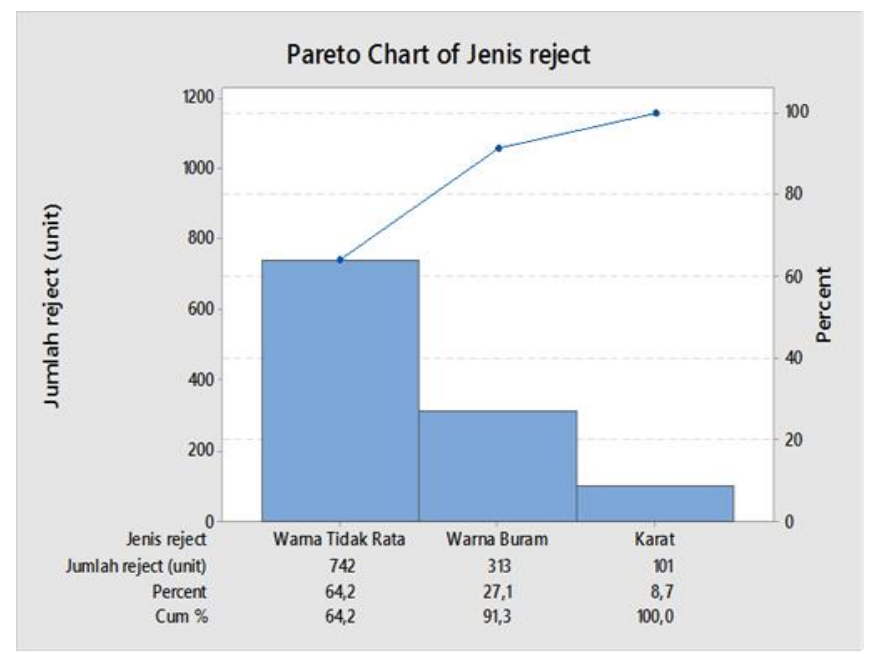

Gambar III. Diagram pareto CTQ

Setelah membuat diagram pareto seperti gambar diatas dapat diketahui jumlah dari masing-masing reject dan dapat diketahui bahwa reject yang paling dominan kecacatannya yaitu reject warna tidak rata sebanyak 742 unit dengan persentase reject sebesar $64 \%$, frekuensi kerusakan warna buram sebesar 313 dengan persentase sebesar $27,1 \%$, selanjutnya jenis kecacatan karat memiliki frekuensi sebesar 101 dengan persentase $8,7 \%$. Berdasarkan pada prinsip pareto $20 \%$ masalah utama mewakili $80 \%$ masalah lainya, maka kecacatan yang melewati $20 \%$ yaitu warna tidak rata merupakan masalah utama atau masalah yang menjadi prioritas untuk dianalisa sehingga kecacatan tersebut dapat di minimalisir.

\section{Measure}

Measure dilakukan untuk menilai kondisi proses yang ada, diantaranya mengukur kinerja sekarang (current performance) tingkat proses dan kemampuan proses untuk ditetapkan sebagai baseline kinerja pada awal proyek six sigma. Setelah dilakukan pendefinisian masalah atau kecacatan akan dilakukan perbaikan, pada fase measure dilakukan perhitungan six sigma untu mengetahui sigma level. Dimana semakin tinggi nilai sigma maka semakin baik kapabilitas proses perusahaan. Berikut dalah tabel perhitungan nilai DPMO dan level sigma:

Tabel VII. Perhitungan Sigma Level

\begin{tabular}{cccccccccc}
\hline & Jumla & \multicolumn{3}{c}{ Jenis Cacat } & & & & \\
\cline { 5 - 8 } $\begin{array}{c}\text { Periode } \\
\text { ke- }\end{array}$ & $\begin{array}{c}\mathrm{h} \\
\text { produ } \\
\text { ksi }\end{array}$ & $\begin{array}{c}\text { Kara } \\
\mathrm{t}\end{array}$ & $\begin{array}{c}\text { Warna } \\
\text { Buram }\end{array}$ & $\begin{array}{c}\text { Warna } \\
\text { Tidak } \\
\text { Rata }\end{array}$ & $\begin{array}{c}\text { Jumlah } \\
\text { Cacat }\end{array}$ & TOP & DPO & DPMO & $\begin{array}{c}\text { LEVEL } \\
\text { SIGMA }\end{array}$ \\
\hline 1 & 2550 & 8 & 30 & 82 & 120 & 7650 & 0,0157 & 15686,3 & 3,65 \\
2 & 2000 & 7 & 12 & 30 & 49 & 6000 & 0,0082 & 8166,67 & 3,90 \\
3 & 2300 & 10 & 20 & 50 & 80 & 6900 & 0,0116 & 11594,2 & 3,77 \\
4 & 2600 & 9 & 35 & 83 & 127 & 7800 & 0,0163 & 16282,1 & 3,64
\end{tabular}


Penerapan Six Sigma Dengan Menggunakan Pendekatan Taguchi Untuk Proses Produksi Elektroplating Produk Spring Tension 35086 Pada PT. Tetra Mitra Sinergis

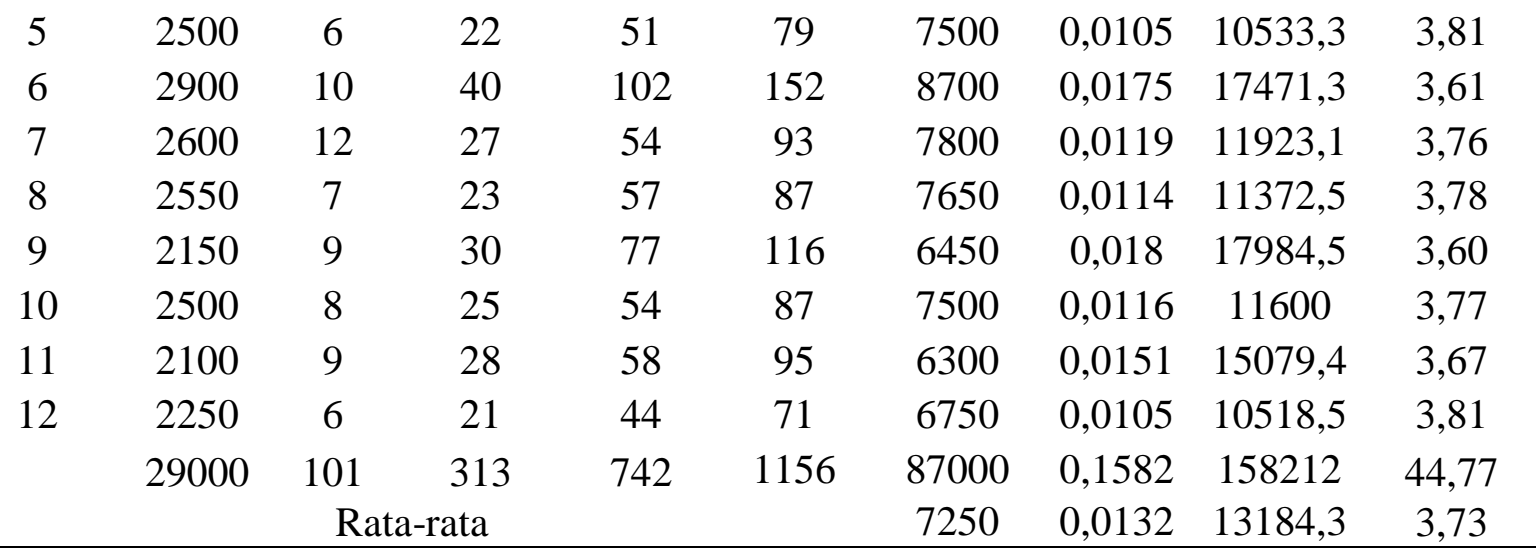

Berdasarkan hasil pengamatan tersebut maka dapat dilihat bahwa produk Spring Tension 35086 tersebut memiliki level sigma 3,73 dengan DPMO rata-rata sebesar 13184,3 unit per satu juta produk. Nilai sigma demikian membuat perusahaan mengalami kerugian.

b. Peta Kendali P

Peta Kendali p merupakan peta kendali yang digunakan untuk melihat proporsi kecacatan yang terjadi pada setiap hasil produksi, dan menggambarkan penyebaran dari penyimpangan seluruh sampel. Berikut ini adalah peta kendali dari produk Spring Tension 35086.

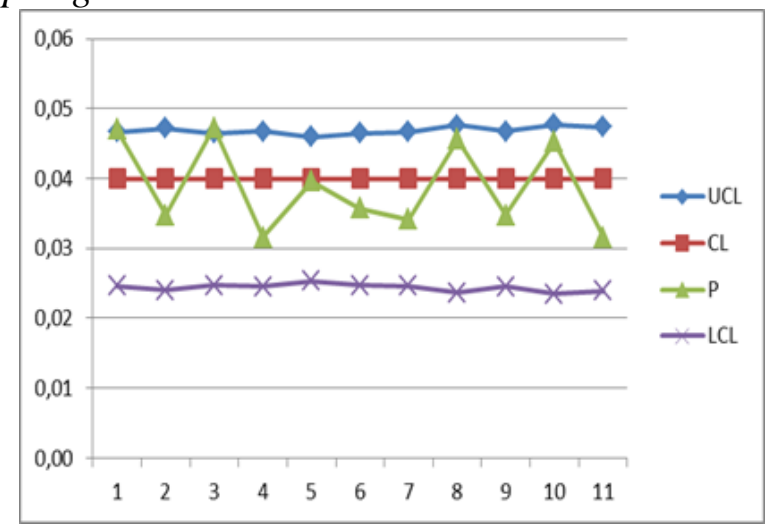

Gambar IV. Grafik Peta kendali P

Dari perhitugngan peta kendali diatas dan setelah dilakukan iterasi sebanyak satu kali maka didapatkan data valid seperti penyajian grafik diatas maka data dinyatakan valid dan bisa dilanjutkan pada perhitungan selanjutnya.

3. Analysis

Tahap analyze dilakukan untuk mengidentifikasi masalah dan menemukan penyebab-penyebab kecacatan yang terjadi pada kualitas produk. Alat yang digunakan pada tahap ini adalah fishbone diagram yang digunakan untuk mencari penyebab dari suatu permasalahan. Untuk membuat diagram fishbone ini data yang diambil dari masalah prioritas yang terdapat pada diagram pareto yang telah dilakukan perhitungan sebelumnya. Diagram sebab akibat ini perlu dilihat dari berbagai faktor, diantaranya dapat disebabkan oleh faktor manusia, mesin, metode, material dan faktor lingkungan. Berikut ini adalah gambar dari diagram fishbone : 


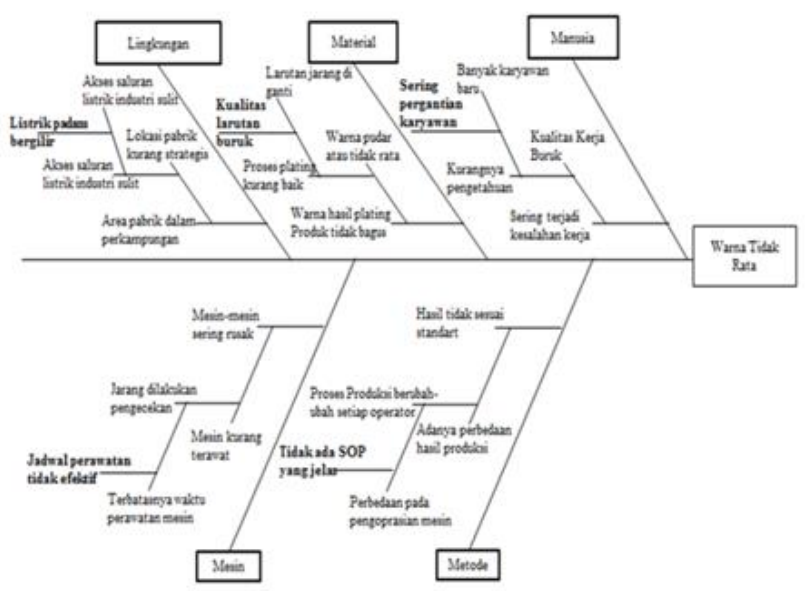

Gambar V. Fishbone diagram

\section{Improve}

a. Metode Taguchi

Pada penelitian diatas dilakukan perbaikan proses dengan menggunakan metode taguchi dengan meneliti faktor-faktor yang munkin mempengaruhia cacat produk Spring Tension 35086 pada PT Tetra Mitra Sinergis. Berikut merupakan langkah-langkah penerapan metode taguchi pada penelitian ini.

1) Penetapan karakteristik kualitas

Untuk penetapan karakteristik kualitas produk Spring Tension 35086 hasil eksperimen yang diharapkan yaitu smaller the better (STB) sehingga karakteristik kualitas yang diamati yaitu cacat atau tidak cacat pada produk Spring Tension 35086 dengan tujuan untuk meminimalisir kategori cacat. Dengan kata lain penetapan karakteristik kualitas yang diinginkan pada Spring Tension 35086 hasil eksperimen yaitu semakin kecil tingkat kecacatan semakin baik.

2) The Loss Function

Fungsi kerugian yang di tanggung ( produsen dan konsumen) akibat kualitas yang dihasilkan PT. Tetra Mitra Sinergis. Bagi produsen yaitu dengan timbulnnya biaya kualitas sedangkan bagi konsumen adanya ketidakpuasan atau kecewa pada produk karena kualitas produk kurang baik.

3) Penetapan Faktor dan Level Berpengaruh

Penetapan Faktor dan Level berpengaruh didapatkan dari studi literatur dan wawancara. Berikut merupakan hasil wawancara dan studi Literatur.

Berdasarkan hasil penelitian, variasi waktu telah menghasilkan perbedaan kualitas lapisan yang sangat signifikan. Untuk penelitian ini digunakan 2 menit, 3 menit, dan 4 menit, Berdasarkan wawancara dan studi literatur suhu yang baik untuk proses elektroplating berada pada 300C, 450C, dan 600C, Untuk penelitian 
Penerapan Six Sigma Dengan Menggunakan Pendekatan Taguchi Untuk Proses Produksi Elektroplating Produk Spring Tension 35086 Pada PT. Tetra Mitra Sinergis

ini tegangan yang digunakan 3 volt, 4,5 volt, dan 6volt, untuk mencapai kualitas lapisan yang diperlukan konsentrasi larutan $1 \%$, $1,2 \%$, dan $1,4 \%$.

Tabel VIII. Level Faktor Berpengaruh

\begin{tabular}{ccccc}
\hline Faktor & \multirow{2}{*}{ Kode } & \multicolumn{3}{c}{ Level } \\
& & 1 & 2 & 3 \\
\hline Waktu pelapisan(mnt) & $\mathrm{A}$ & 2 & 3 & 4 \\
Suhu Reaksi(C) & $\mathrm{B}$ & 30 & 45 & 60 \\
Tegangan/voltase(volt) & $\mathrm{C}$ & 3 & 4,5 & 6 \\
Konsentrasi larutan(\%) & $\mathrm{D}$ & 1 & 1,2 & 1,4 \\
\hline
\end{tabular}

4) Penetapam Orthogonal arayy

Untuk mendapatkan Orthogonal Aray yang sesuai maka diperlukan nilai degree of freedom dari faktor-faktor yang akan digunakan dalam design of eksperimen. Setelah nilai degree of freedom didapatkan, maka tabel Orthogonal Aray yang digunakan sesuai dengan nilai degree of freedom faktor. Pada tabel ini adalah perhitungan degree of fredoom untuk faktor dalam penelitian ini.

Tabel IX. Perhitungan Degree Of Freedom

\begin{tabular}{ccc}
\hline Kode & Faktor Penjelasan & DOF \\
\hline A & Waktu pelapisan(mnt) & $(3-1$ \\
B & Suhu Reaksi(C) & $(3-1)$ \\
C & Tegangan/voltase(volt) & $(3-1)$ \\
D & Konsentrasi larutan(\%) & $(3-1)$ \\
\hline Total & & 8 \\
\hline
\end{tabular}

Pada tabel diatas diketahui bahwa nilai degree of freedom dari faktor penelitian ini adalah delapan. Berdasarkan penjelasan pada tabel diatas, maka pada penelitian ini harus dilakukan eksperimen dengan menggunakan Orthogonal Aray L8=34, namun dikarenakan pada eksperimen taguchi tidak mengenal adanya Orthogonal Aray L8=34, maka untuk kepentingan penelitian ini jumlah Orthogonal Aray harus dinaikan menjadi Orthogonal Aray L9=34, agar penelitian ini dapat dilakukan sesuai dengan kaidah penelitian Taguchi.

Tabel X. Orthogonal Aray L9=34

\begin{tabular}{cccccc}
\hline Run\# & $\mathrm{a}$ & $\mathrm{b}$ & $\mathrm{c}$ & $\mathrm{d}$ & $\mathrm{X}$ \\
\hline 1 & 1 & 1 & 1 & 1 & $\mathrm{X} 1$ \\
2 & 1 & 2 & 2 & 2 & $\mathrm{X} 2$ \\
3 & 1 & 3 & 3 & 3 & $\mathrm{X} 3$ \\
4 & 2 & 1 & 2 & 3 & $\mathrm{X} 4$ \\
5 & 2 & 2 & 3 & 1 & $\mathrm{X} 5$ \\
6 & 2 & 3 & 1 & 2 & $\mathrm{X} 6$ \\
7 & 3 & 1 & 3 & 2 & $\mathrm{X} 7$ \\
8 & 3 & 2 & 1 & 3 & $\mathrm{X} 8$ \\
9 & 3 & 3 & 2 & 1 & $\mathrm{X} 9$ \\
\hline
\end{tabular}


5) Pelaksanaan eksperimen

Pada tahap pelaksanaan eksperimen taguchi akan dilakukan pencatatan terhadap produk Spring Tension 35086 berdasarkan jenis kecacatan yaitu karat, warna buram, warna tidak rata. Apabila dalam proses 1 pcs produk Spring Tension 35086 mengandung kecacatan ke 3 unsur kecacatan tersebut maka akan dihitung sebagai produk cacat. Pada penelitian ini dilakukan 3 kali replikasi untuk masing-masing kombinasi level faktor berpengaruh.

Tabel XI. Hasil Eksperimen Taguchi

\begin{tabular}{cccccccc}
\hline \multirow{2}{*}{ Eks } & \multicolumn{3}{c}{ Faktor Kontrol } & \multicolumn{3}{c}{ Hasil } \\
\cline { 2 - 8 } & A & B & C & D & I & II & III \\
\hline 1 & 1 & 1 & 1 & 1 & 21 & 24 & 25 \\
2 & 1 & 2 & 2 & 2 & 22 & 21 & 24 \\
3 & 1 & 3 & 3 & 3 & 25 & 27 & 24 \\
4 & 2 & 1 & 2 & 3 & 26 & 27 & 25 \\
5 & 2 & 2,0 & 3 & 1 & 23 & 24 & 24 \\
6 & 2 & 3 & 1 & 2 & 21 & 22 & 23 \\
7 & 3 & 1 & 3 & 2 & 26 & 26 & 27 \\
8 & 3 & 2 & 1 & 3 & 28 & 26 & 24 \\
9 & 3 & 3 & 2 & 1 & 22 & 21 & 24 \\
\hline
\end{tabular}

6) Perhitungan ANOVA

Metode taguchi menggunakan Analysis of Variance (ANOVA) data atribut bertujuan untuk mencari faktor-faktor yang mempengaruhi nilai respon. Analysis of Variance (ANOVA) merupakan metode yang digunakan untuk mencari setting level optimal guna meminimalkan penyimpangan variansi. Berikut ini langkah-langkah perhitungan Analysis of Variance (ANOVA) untuk data atribut.

Tabel XII. Hasil Perhitungan Rata-Rata Cacat

\begin{tabular}{ccccccccc}
\hline \multirow{2}{*}{ Eks } & \multicolumn{4}{c}{ Faktor Kontrol } & \multicolumn{3}{c}{ Hasil } & \multirow{2}{*}{ Rata-rata } \\
\cline { 2 - 7 } & A & B & C & D & I & II & III & \\
\hline 1 & 1 & 1 & 1 & 1 & 21 & 24 & 25 & 23,3333 \\
2 & 1 & 2 & 2 & 2 & 22 & 21 & 24 & 22,3333 \\
3 & 1 & 3 & 3 & 3 & 25 & 27 & 24 & 25,3333 \\
4 & 2 & 1 & 2 & 3 & 26 & 27 & 25 & 26 \\
5 & 2 & 2 & 3 & 1 & 23 & 24 & 24 & 23,6667 \\
6 & 2 & 3 & 1 & 2 & 21 & 22 & 23 & 22 \\
7 & 3 & 1 & 3 & 2 & 26 & 26 & 27 & 26,3333 \\
8 & 3 & 2 & 1 & 3 & 28 & 26 & 24 & 26 \\
9 & 3 & 3 & 2 & 1 & 22 & 21 & 24 & 22,3333 \\
\hline
\end{tabular}

Dari hasil perhitungan rata-rata diatas yaitu menjumlahkan hasil eksperimen bulan ke I,II, dan III kemudian dibagi 3 (3 kali 
Penerapan Six Sigma Dengan Menggunakan Pendekatan Taguchi Untuk Proses Produksi Elektroplating Produk Spring Tension 35086 Pada PT. Tetra Mitra Sinergis

pengujian) untuk mengetahui lebih jelasnya dapat dilihat pada tabel ANOVA.

Tabel XIII. Tabel Respon

\begin{tabular}{ccccc}
\hline FAKTOR & A & B & C & D \\
\hline 1 & 23,67 & 25,22 & 23,78 & 23,11 \\
2 & 23,89 & 24 & 23,56 & 23,56 \\
3 & 24,89 & 23,22 & 25,11 & 25,78 \\
DIFFERENT & 1,22 & 2 & 1,56 & 2,67 \\
RANKING & 4 & 2 & 3 & 1 \\
\hline
\end{tabular}

Dari perhitungan tabel respon diatas didapatkan hasil bahwa level faktor yang berpengaruh adalah faktor A1 waktu pelapisan 2 menit, B3 suhu reaksi 600C,C2 Tegangan 4,5 volt, dan D1 konsentrasi larutan $1 \%$.

Tabel XIV. Tabel Analysis Of Variance (ANOVA)

\begin{tabular}{ccccccc}
\hline Sumber & SS & DF & MS & Fratio & SS' & RATIO\% \\
\hline A & 15754,6 & 2 & 7877,31 & 0,25883 & 76624,2 & 4,27257 \\
B & 15761,0 & 2 & 7880,48 & 0,25893 & 76630,6 & 4,27292 \\
C & 15759,7 & 2 & 7879,83 & 0,25891 & 76629,3 & 4,27285 \\
D & 15783,8 & 2 & 7891,89 & 0,2593 & 76653,4 & 4,27419 \\
e & 60869,6 & 2 & 30434,8 & 1 & 28860,3 & 1,60925 \\
SST & 17934 & 26 & - & - & - & - \\
Mean & 15744,6 & 1 & - & - & - & - \\
\hline Sstotal & & 37 & - & - & - & 18,7018 \\
\hline
\end{tabular}

Berdasarkan hasil perhitungan Analysis of Variance dari perhitungan diatas bahwa masing-masing faktor memiliki kontribusi yang sangat signifikan dengan total $18,7018 \%$ hal ini menunjukan bahwa taguchi mampu mengurangi produk cacat Spring Tension 35086.

7) Perhitungan Signal to Noise Ratio

Signal to Noise Ratio rancangan untuk transformasi pengulangan data ke dalam suatu nilai yang merupakan ukuran variasi yang timbul (Fajar Rahmadi, 2010). Perhitungan Signal to Noise Ratio bertujuan untuk mengetahui faktor-faktor mana saja yang berpengaruh pada eksperimen ini SNR yang digunakan pada penelitian ini adalah Smaller the Better yang memiliki karakteristik semakin kecil semakin baik. Berikut langkah-langkah pengujian ANOVA Signal to Noise Ratio (SNR). 
Tabel XV. Hasil Perhitungan SNR

\begin{tabular}{|c|c|c|c|c|c|c|c|c|c|}
\hline \multirow{2}{*}{ Eks } & \multicolumn{4}{|c|}{ Faktor Kontrol } & \multicolumn{3}{|c|}{ Hasil } & \multirow{2}{*}{ MSD } & \multirow{2}{*}{$\mathrm{S} / \mathrm{N}$} \\
\hline & $\mathrm{A}$ & $\mathrm{B}$ & $\mathrm{C}$ & $\bar{D}$ & I & II & III & & \\
\hline 1 & 1 & 1 & 1 & & 21 & 24 & 25 & 547 & $-27,383$ \\
\hline 2 & 1 & 2 & 2 & 2 & 22 & 21 & 24 & 33 & $-26,993$ \\
\hline 3 & 1 & 3 & 3 & 3 & 25 & 27 & 24 & 3 & $-2 \varepsilon$ \\
\hline 4 & 2 & 1 & 2 & 3 & 26 & 27 & 25 & 67 & $-28,304$ \\
\hline 5 & 2 & 2 & 3 & 1 & 23 & 24 & 24 & 56 & $-27,484$ \\
\hline 6 & 2 & 3 & 1 & 2 & 21 & 22 & 23 & 484, & $-26,854$ \\
\hline 7 & 3 & 1 & 3 & 2 & 26 & 26 & 27 & & $-28,412$ \\
\hline 8 & 3 & 2 & 1 & 3 & 28 & 26 & 24 & 678,667 & $-28,317$ \\
\hline 9 & 3 & 3 & 2 & 1 & 22 & 21 & 24 & 500,333 & $-26,993$ \\
\hline
\end{tabular}

Tabel XVI. Tabel Respon SNR

\begin{tabular}{ccccc}
\hline FAKTOR & A & B & C & D \\
\hline 1 & $-27,49$ & $-28,03$ & $-27,52$ & $-27,29$ \\
2 & $-27,55$ & $-27,6$ & $-27,43$ & $-27,42$ \\
3 & $-27,91$ & $-27,31$ & $-27,99$ & $-28,23$ \\
DIFFERENT & 0,42 & 0,72 & 0,56 & 0,95 \\
RANKING & 4 & 2 & 3 & 1 \\
\hline
\end{tabular}

Dari hasil tabel respon Signal to Noise Ratio tersebut, dipilihlah nilai level faktor paling kecil pada setiap faktor, hal ini digunakan sebagai penerapan Signal to Noise Ratio pada Smaller The Better.

8) Penentuan Setting Level Optimal

Berikut merupakan tabel perbandingan pengaruh kombinasi faktor dan level pada eksperimen taguchi terhadap kualitas produk Spring Tension 35086.

Tabel XVII. Perbandingan Pengaruh Faktor

\begin{tabular}{ccc}
\hline Faktor & \multicolumn{1}{c}{ Pengaruh } & Setting Level yang digunakan \\
\hline A & Signifikan dan kontribusi besar & A3 \\
B & Signifikan dan kontribusi besar & B1 \\
C & Signifikan dan kontribusi besar & C3 \\
D & Signifikan dan kontribusi besar & D3 \\
\hline
\end{tabular}

Berdasarkan tabel diatas dapat dikethui bahwa kombinasi level optimal yaitu faktor A level 3 dengan waktu pelapisan 4 menit. Kemudian faktor B level 1 dengan suhu reaksi 300C. Kemudian faktor C level 3 dengan tegangan/voltase 6 volt. Kemudian faktor D level 3 dengan konsentrasi larutan 1,4\%.

5. Control

Pada tahap control dilakukan pengecekan pada line produksi elektropleting PT. Tetra Mitra Sinergis. Pengecekan dilakukan oleh bagian QC sebelum proses produksi elektroplating dilakukan, apabila pada proses pengecekan terdapat level faktor tidak sesuai dengan sistem yang telah ditetapkan maka 
Penerapan Six Sigma Dengan Menggunakan Pendekatan Taguchi Untuk Proses Produksi Elektroplating Produk Spring Tension 35086 Pada PT. Tetra Mitra Sinergis

pihak QC memberikan peringatan poka yoke pada line produksi tersebut. Warning poka yoke yang paling tepat digunakan pada penelitian ini adalah berupa lampu indikator pada line produksi. Apabila lampu indikator berwarna hijau maka line produksi berstatus OK dan siap digunakan, tetapi apabila lampu indikator berwarna merah maka pihak QC memberikan warning poka yoke yang berarti line produksi tidak bisa digunakan.

\section{Kesimpulan}

Berdasarkan hasil penelitian yang telah dilakukan untuk produk Spring Tension 35086 dengan warna plating Rainbow Cr3 pada PT. Tetra Mitra Sinergis didapatkan simpulan telah diketahui nilai sigma pada periode pertama sebesar 3,65 dengan memiliki nilai DPMO 15686,3 pada periode kedua mengalami kenaikan nilai sigma sehingga mendapatkan nilai sebesr 3,90 dengan nilai DPMO 8166,67, kemudian pada periode ketiga mengalami penurunan nilai sigma sehingga menjadi 3,77 dengan nilai DPMO sebesar 11594,67, kemudian pada periode keempat kembali mengalami penurunan nilai sigma sehingga menjadi 3,64 dengan nilai DPMO sebesar 16282,1, kemudian pada periode kelima mengalami kenaikan nilai sigma sehingga menjadi 3,81 dengan nilai DPMO sebesar 10533,3, kemudian pada periode keenam mengalami penurunan nilai sigma sehingga menjadi 3,61 dengan nilai DPMO sebesar 17471,3, kemudian pada periode ketujuh mengalami kenaikan nilai sigma sehingga menjadi 3,76 dengan nilai DPMO sebesar 11923,1, kemudian pada periode kedelapan mengalami kenaikan nilai sigma sehingga menjadi 3,78 dengan nilai DPMO sebesar 11372,5, kemudian pada periode kesembilan mengalami penurunan nilai sigma sehingga menjadi 3,60 dengan nilai DPMO sebesar 17984,5, kemudian pada periode kesepuluh mengalami kenaikan nilai sigma sehingga menjadi 3,77 dengan nilai DPMO sebesar 11600, kemudian pada periode kesebelas mengalami penurunan nilai sigma sehingga menjadi 3,67 dengan nilai DPMO sebesar 15079, kemudian pada periode kedua belas mengalami kenaikan nilai sigma sehingga menjadi 3,81 dengan nilai DPMO sebesar 10518,5. Terdapat 3 jenis CTQ (critical to quality) yaitu karat, warna buram, warna tidak rata dan dapat diketahui bahwa terdapat 1 jenis reject yang paling dominan kecacatannya yaitu reject warna tidak rata sebanyak 742 unitdengan persentase reject sebesar $64 \%$. Setelah dilakukan penelitian dikethui bahwa kombinasi level optimal yaitu faktor A level 3 dengan waktu pelapisan 4 menit, Kemudian faktor B level 1 dengan suhu reaksi 300C, Kemudian faktor C level 3 dengan tegangan/voltase 6 volt, Kemudian faktor D level 3 dengan konsentrasi larutan 1,4\%, Kombinasi faktor dan level hasil eksperimen taguchi diharapkan dapat meminimalisir terjadinya cacat Product collapse. Produk yang dirancang dengan menggunakan Taguchi method ini akan memberikan kinerja yang lebih konsisten dan membuat proses bersifat kokoh (robust) terhadap faktor gangguan (noise). 
Habib Fiki Wahyudi, Zeny Fatimah Hunusalela dan Anggi Oktaviani

\section{Bibliografi}

Anggraini, Dian, Dewi, Shanty Kusuma, \& Saputro, Thomy Eko. (2015). Aplikasi Metode Taguchi Untuk Menurunkan Tingkat Kecacatan Pada Produk Paving. Jurnal Teknik Industri, 16(1), 1-9.

Asfar, Mukhammad, Tjahjaningsih, Yustina Suhandini, \& Haryono, H. (2018). Pengendalian Kualitas Produk Bata Ringan AAC dengan Metode Taguchi di PT AFU 28. ENERGY, 8(2), 49-58.

Caesaron, Dino, \& Simatupang, Stenly Yohanes P. (2015). Implementasi pendekatan DMAIC untuk perbaikan proses produksi pipa PVC (studi kasus PT. Rusli Vinilon). Jurnal Metris, 16(2), 91-96.

Gusniar, Iwan Nugraha. (2012). ANALISIS KUALITAS TUAS REM BELAKANG SEPEDA MOTOR DI INDUSTRI KECIL PT. X DENGAN METODE TAGUCHI. Majalah Ilmiah SOLUSI, 11(24).

Harsanto, Budi. (2017). Dasar Ilmu Manajemen Operasi. Unpad Press.

Oktajayanti, Nesvi Intan, Mustafid, Mustafid, \& Sudarno, Sudarno. (2016). Pendekatan Metode Six Sigma-taguchi Dalam Meningkatkan Kualitas Produk (Studi Kasus PT. Asaputex Jaya Spinning Mill Tegal). Jurnal Gaussian, 5(1), 163-172.

Ramayanti, Gina, Fitriyeni, Lailatul, \& Yulistyari, Eka Indah. (2019). Usulan Peningkatan Kualitas Batu Merah dengan Metode Six Sigma dan Taguchi. Penelitian Dan Aplikasi Sistem Dan Teknik Industri, 13(1), 9-16.

Schroeder, Roger G., Goldstein, Susan M., \& Rungtusanatham, M. Johny. (2011). Operations Management 5th edition. Avenue of The Americans. New York: McGraw-Hill.

Shofia, Nailatis, Mustafid, Mustafid, \& Sudarno, Sudarno. (2015). Kajian Six Sigma Dalam Pengendalian Kualitas Pada Bagian Pengecekan Produk DVD Players PT X. Jurnal Gaussian, 4(1), 71-81.

Soejanto, Irwan. (2009). Desain eksperimen dengan metode taguchi. Yogyakarta: Graha Ilmu.

Sufandy, S. (2018). Pengaruh Total Quality Management (TQM) Terhadap Kinerja Pegawai Pada PT. Bank Negara Indonesia (BNI) 46 Persero Tbk. Makasar.

Wijaya, William Dwi, \& Sutapa, I. Nyoman. (2013). Upaya Pengurangan Tingkat Kecacatan Cabai Pasca Panen Pada Jalur Rantai Pasok. Jurnal Titra, 1(2), 253256.

Yamit, Zulian. (2010). Manajemen Kualitas Produk dan Jasa, Ekonisia. Yogyakarta. 